\title{
Sublimação: um destino possível? 49
}

\section{Sissi Vigil Castiel5o}

A sublimação é o mecanismo psíquico postulado por Freud que explica as criações humanas no plano da cultura e parte da premissa de que a sexualidade estaria na origem desses processos, porque passaria por uma transformação devido a sua plasticidade. Assim, seria possível, através de uma simbolização, que ela desse origem às realizações humanas em outro campo que não o originariamente pretendido. Mesmo que tenha sido trabalhado por Freud do início ao fim de sua obra, segue até hoje contendo numerosos enigmas, por exemplo, que relações guarda com a sexualidade no que diz respeito ao desvio das metas sexuais para algo socialmente valorizado. O que se coloca em destaque na transformação dos desejos para que sejam aceitos socialmente é uma visão normativa do processo sublimatório como se ele fosse um conceito moral e, com isso, transforma-se em sinônimo de arte e de sublime e a dimensão de processo psíquico torna-se reduzida. Esses impasses resultaram que ela tenha, muitas vezes, sido deixada de lado, situando-se numa posição idealizada e, por isso mesmo, na ordem do impossível. E é indiscutivelmente interessante desde o ponto de vista da clínica retomar essa noção para abordar sua especificidade, bem como as diferenças de outros mecanismos psíquicos. Entendo que a positividade do processo sublimatório e função na clínica encontram-se relacionadas a ideia de um psiquismo funcionando em um nível simbólico e de abstração, capaz de uma transformação pulsional: diante da impossibilidade de satisfação do desejo, criar alternativas não diretamente sexuais, mas sem abrir mão de uma posição desejante. Assim, são esses aspectos que tentarei desenvolver, brevemente, nesta fala.

Dentre as inúmeras vezes em que ela foi tratada por Freud, vou me referir a duas que, em minha opinião, particularmente, a retiram desses entraves trazendo possiblidade de enxergá-la como processo psíquico. A primeira é a que a define

\footnotetext{
49 Trabalho apresentado na mesa "Sublimação: um destino possível?” no II Simpósio Bienal SBPSP "Fronteiras da Psicanálise: a clínica em movimento" no dia 22 de agosto de 2020.

5o Psicanalista, doutora em psicanálise pela Universidade Autônoma de Madri, membro pleno da Sigmund Freud Associação Psicanalítica de Porto Alegre, autora de Sublimação: clínica e metapsicologia, 2007, Escuta.
} 
como um dos quatro destinos pulsionais e a segunda que a aproxima de Eros e da capacidade de ligação.

Primeiramente, dentro do contexto de $1914^{51}$, o narcisismo como período que caracteriza a sexualidade infantil é o momento do desenvolvimento da libido no qual a satisfação não pode prescindir da dimensão corporal; a fonte e o objeto da pulsão são uma parte do próprio corpo do sujeito. E como, ao longo do tempo a sexualidade infantil, não pode ser satisfeita sempre, sofre destinos. Nesse sentido, em Pulsões e suas vicissitudes52 (1915), Freud afirma que a volta contra si mesmo e a transformação no contrário fazem parte da organização narcisista. Em contraposição, os dois ulteriores que são o recalque e a sublimação são mais evoluídos porque estariam fora da organização narcisista e possibilitariam lidar com o pulsional de outra forma que não a satisfação no próprio corpo do sujeito, através de sua expulsão da consciência no recalque ou de uma realização pulsional alternativa na sublimação.

O que está em pauta no recalque é colocar fora de ação um determinado impulso. Dessa forma, a sexualidade só terá uma satisfação diretamente corporal novamente a partir da puberdade. Até lá, isto se dará de forma simbólica, afastando-se da dimensão corporal o que constitui a sublimação como um destino posterior ao recalque; caracteriza-se por ser uma realização pulsional simbólica e alternativa que contém uma transformação da meta e do objeto. Entendo que é por essa razão que Freud utiliza esta palavra, no sentido da evaporação, da passagem do sólido ao gasoso. O que se sublima são as pulsões parciais de ver, de exibir-se, de maltratar e de ser maltratado.

Desde outro ponto de vista, existe uma relação entre a formação dos ideais e afastamento do narcisismo o que, na minha opinião, se aproxima da sublimação. É dentro do contexto da metapsicologia de $1915^{53}$, que Freud aborda a questão da formação dos ideias como o substituto do narcisismo perdido da infância na qual o sujeito era seu próprio ideal. Dentro desse contexto, a idealização diz respeito ao aferramento ao objeto que equilibraria o narcisismo do sujeito, por ela, ele é engrandecido e exaltado. Enquanto que a sublimação relaciona-se a libido objetal, ou seja, consiste no fato da libido poder se dirigir a outros objetos, a partir de uma finalidade diferente e afastada da sexualidade.

${ }^{51}$ FREUD, S. (1914). Sobre o narcisismo: uma introdução. Vol. XIV.

$5^{2}$-FREUD, S. (1915). Os instintos e suas vicissitudes. Vol. XIV.

53 FREUD, S. (1914). Sobre o narcisismo: uma introdução. Op. Cit. 
A castração implica o fim do narcisismo (como período) e a perda da de encontro carnal com a mãe; é preciso separar-se do objeto primário como objeto de satisfação. Esta como presença está condenada a erotização do vínculo com o filho, fonte da psicose ou da histeria. O triangulo edípico assim constituído possibilita a construção da imago materna por sua ausência que é compensada pelo pai não agressor como uma presença com a qual o sujeito pode se identificar. A operação permite ao sujeito se dirigir ao outro como alteridade o que reordena seu campo, na medida em que se tornam possíveis relações mediadas pelo símbolo e pela palavra, a transformação do ego ideal em ideal de ego e a sublimação ao invés da idealização. Há uma articulação da sublimação com o Édipo, na medida em que estaria relacionada a uma desamarração do narcisismo a partir da castração. Para tanto, é necessário a interiorização da ausência do objeto primário como fator imprescindível à simbolização e a relação com o outro como alteridade.

Isto implica pensar na dimensão da perda dos objetos e complexizar a relação entre sublimação e trabalho de luto. Em Luto e melancolia54 (1917) Freud demonstrou que no trabalho do luto o desinvestimento do objeto perdido ocorre paulatinamente, havendo uma elaboração da perda na medida em que o sujeito pode ir descolando-se de uma posição de fixidez para criar a possibilidade de retornar a ligação da libido com o mundo e de estabelecer novos investimentos objetais. O lugar vazio do objeto torna-se fonte de novas oportunidades de laços objetais, promovendo uma separação entre o objeto e o si mesmo, entre o lugar simbólico que ele ocupava e o ego, de forma que este se torna capaz de consentir a perda que o fim dos laços com o objeto causa.

É a partir do retorno da libido investida nos objetos ao ego que inicia o processo sublimatório, portanto, há um investimento libidinal no eu. Ele transforma-se em objeto para substituir o objeto perdido ou para fazer-se amar em seu lugar. Trata-se de um trabalho de luto objetal bem sucedido composto de dois momentos: o eu se coloca como objeto na linha de substituição da perda para mais tarde encontrar outros objetivos e objetos. O ego media o processo colocando um tempo intermediário. Esta é a diferença entre sublimação e identificação, nesta última o objeto perdido instala-se no ego e este se apropria de alguns de seus traços. Já na primeira, trata-se de uma substituição objetal.

54 FREUD, S. (1917). Luto e melancolia. Vol. XIV. 
Green (2006)55 aborda a importância do trabalho psíquico de desapego dos objetos primários no decorrer do desenvolvimento do psiquismo. O trabalho e a possiblidade de criação a partir da ausência é o que vem a constituir o trabalho do negativo em sua positividade para o autor. Quando um sujeito pode se desligar do objeto primário sem grandes danos, o investimento é objetalizado. Nesse sentido, o trabalho do negativo comporta uma função objetalizante. Esta consiste em transformar em objeto algo que não estava nessa categoria, caracteriza-se pelo investimento significativo, ou seja, mais do que o objeto em si, a objetalização diz respeito a capacidade de investir e criar. Nessa medida, considerando-se a importância de se levar em conta o aspecto da criação e simbolização presente no processo sublimatório, não seria dentro deste contexto que se poderia pensar a sublimação como um processo psíquico na linha da efetividade do trabalho do negativo e da função objetalizante? Ainda que Green tenha outro entendimento desse conceito, suas formulações me permitem encontrar eco para abordar esta relação. Pois, dimensiona a ideia de que a criação presente caracteriza-se pela capacidade de potencializar os investimentos pulsionais em direção a alteridade através de múltiplos objetos. Diz respeito a capacidades elaborativas e simbólicas que contém um efeito germinativo. Nessa perspectiva, o objeto sublimado não é fixo, simplesmente uma substituição de um para outro, trata-se da capacidade de criar indefinidamente variados objetos.

Por fim, trato da relação da sublimação com a pulsão de vida e com os processos de ligação, em contraposição a pulsão de morte e a ao desligamento. Freud(1923) ${ }^{6}$ se refere a libido que reflui dos objetos como energia libidinal dessexualizada, é uma energia deslocável e pode ser acrescentada a uma ou outra das classes pulsionais. É a plasticidade da pulsão sexual que permite o deslocamento e assim possibilita a ligação da libido a objetos substitutos, simbólicos dos objetos primordiais. A simbolização - a articulação entre representação e representação palavra, fundamenta a ligação. Estas são as atividades principais de Eros. Enquanto que, se a libido dessexualizada for acrescentada à pulsão de morte acarreta a desfusão pulsional e a liberação da agressividade. A ligação e o desligamento indicam direções opostas, no entanto, estas forças coabitam o psiquismo, os processos não são puros. A ligação é um

55 GREEN, A. (2006). El trabajo de lo negativo. Buenos Aires: Amorrortu. ${ }^{6} 6$ FREUD, S. (1923). O ego e o id. Vol. XIX. 
possibilidade de fusionar as duas classes pulsionais, mas que ocorre paulatinamente a desligamentos e desfusões. Isto implica perceber a sublimação como uma tendência à ligação possível a partir da simbolização da ausência do objeto, mas não é um caminho linear pré-estabelecido que o sujeito atingiria como sinal de maturidade que sua relação com o Édipo, a castração e o ultrapassamento do narcisismo poderiam indicar; é uma tendência.

Em um texto anterior57, trabalhei a ideia de que é justamente a partir da segunda dualidade pulsional que a sublimação pode ser conceituada em Freud não em oposição ao sexual, mas de acordo com Eros. Este engloba a sexualidade manifesta e a que auxilia na conservação do sujeito, já que se opõe à morte e o faz criar unidades cada vez maiores em torno de si. Esta postulação torna possível supor que existem duas formas da sexualidade: a manifesta ou recalcada e a que se apresenta como sublimação, que não deixa de ser sexualidade, ainda que não se manifeste diretamente como tal e que permite novas formas de satisfação. Nesse sentido, sublimar significa levar em conta o prazer da criação e uma posição desejante.

Por fim, poderia dizer que sublimar relaciona-se a uma simbolização que tem como fundamento a ausência do objeto de completude e isto implica ligação e criação de laços com os objetos em uma dimensão de alteridade, em contraposição ao desligamento da pulsão de morte onde haveria o seu fracasso. Esta objetalização se distancia da dimensão corporal, mas leva em conta o desejo e o prazer.

Dado que é imperioso para o psiquismo a simbolização da ausência e a ligação a objetos como uma manifestação de Eros, que relação teria a sublimação com a experiência analítica? Entendo que o sucesso da análise depende do quanto se consegue ultrapassar a adesividade da libido a formas masoquistas de satisfação, a inércia psíquica como expressão da compulsão a repetição, a reação terapêutica negativa e a descarga, característica da pulsão de morte.

A tarefa analítica não se completa com o conhecimento do desejo, essa seria somente uma parte do processo. Talvez a dimensão terapêutica da análise relacione-se aos batalhões de Eros, como diz Freud $5^{8}$ em um momento mais tardio de suas formulações técnicas, onde afirma que o acesso à sublimação é uma das

57 CASTIEL, S. (2007). Sublimação: clínica e metapsicologia. São Paulo: Escuta.

$5^{8}$ FREUD, S. (1937). Análise Terminável e interminável. Vol. XXIII. 
metas da cura, articulando, desta forma, a teoria da cura ao processo sublimatório. O sujeito é marcado por fixações e destinos aprisionadores e a experiência analítica propõe a chance de romper com eles, através de sua desconstrução, para relançar o sujeito em sua possibilidade de desejar e de ter uma existência inventiva.

Atualmente estamos vivendo uma situação de traumatismo que alcança uma dimensão coletiva e por isso excede a perspectiva subjetiva e fantasmática. A morte, o desamparo e a solidão se colocam como presenças a serem consideradas para si e para o outro. Em função disso, os traços melancólicos tem aparecido com frequência. Entendo que o desligamento dos objetos e da vida vivida até então, podem implicar na desfusão e no desligamento frente aos quais o ego responde de forma masoquista. A inscrição psíquica do acontecimento se impõe.

O trabalho clínico que estamos desenvolvendo nesse momento, se relaciona a promover a ligação, a Eros em detrimento do desligamento e da melancolia. Desde o ponto de vista econômico, as possibilidades elaborativas se relacionam a capacidade de ligação da energia psíquica para posterior simbolização e assim se aproxima do problema da sublimação, no sentido de ultrapassar as limitações impostas e poder criar dentro do que é possível. Em minha opinião, essa é a importância da consideração desse conceito, poder enxergá-lo como um processo que ocorre em um psiquismo capaz de simbolizar, ligar e objetalizar e que por isso mesmo pode estar no horizonte da clínica. 